\title{
Evidence from North Carolina shows that immigrant students with limited English have a very minor impact on native students' performance
}

\begin{abstract}
Much of the recent concern about undocumented immigration into the U.S. can be linked to the perceived burden that these immigrants may create on the public education system. But is this really the case? Through analyzing detailed information on the performance of students in North Carolina, Timothy M. Diette and Ruth Uwaifo Oyelere find that the presence of students with limited English does have a negative, though small, effect on the math and reading achievement of natives that are male and black. They argue, however, that these effects are so small as not to warrant policy interventions.
\end{abstract}

The recent surge of immigrants, particularly from Latin America, has sparked debates on U.S immigration policy and concerns over the potential negative effects. One of the arguments against the recent wave of immigration is the perceived burden it creates on the public education system. People are concerned about the explicit costs, such as additional staff and materials, as well as the implicit cost of harming the education of students already in schools in the United States. But, do students learning to speak English really harm native students? And if so, how large is the effect and is it the same impact across female and male students or across students of different races? In new research, we find that while black and white male students do experience some negative effects, but that these are not large enough to justify significant policy concerns.

While it is easy to conceptualize how an increase in immigrants can increase public school spending, it is not clea why we should infer that they should create negative effects on native students. From one perspective, immigrant families are a select group of people. If the parents come to the U.S. through an $\mathrm{H}$ or other work related visa they may be highly educated. Even lower educated immigrants do not represent a random draw of individuals, rather they are willing to take risks and put in the effort to travel to a foreign country in search of a better life. In this scenario, exposure to children from families with high levels of human capital or other valuable characteristics such as grit can create positive learning externalities for native students.

Those with expectations that immigrants will harm the education of native U.S. students may focus on the potential effects of immigrants coming from a relatively low socio-economic background and having difficulty with the English language. In this view, the students may require the attention of teachers to address their learning challenges. In addition students could also be disruptive to the class and may be negative role models to the native students.

We focused our research on a subset of immigrant children, those identified as having Limited English (LE) proficiency. Many view these students as those who are most likely to create negative effects on native U.S. students. We make use of a methodology that eliminates unobservable characteristics associated with time and individual schools which otherwise can lead to biased estimates of the effects of LE students.

Our focus was on North Carolina. Why? The foreign born population in North Carolina has increased significantly in recent decades, such that the immigrant share of the population increased from just 1 percent in 1990 to 7 percent by 2008. And, between 1990 and 2004 the Latino population in North Carolina grew from 76,000 to nearly 600,000. In addition, our analysis requires significant detailed information on students and their test performance over time and North Carolina is one of the few states with detailed demographic information on all students in public schools as well as their education records. We accessed this information from the North Carolina Education Research Data Center (NCERDC) at Duke University for between 1998 and 2006. 
In a previous paper, we tested whether, on average, native students experience negative peer effects from increased exposure to LE students. We found evidence of negative effects on the math and reading achievement of natives. However, the magnitude of the effects was small. Given past research that has shown differential responses to school related inputs by gender and race, in our new work, we decided also to investigate if the negative average impact of LE students on natives is similar across race and gender of native students.

To investigate gender differences, we divide our sample of non-Limited English students into males and females and test for LE peer effects for each group. Our results show no negative effects on girls and negative effects on boys in both reading and math. Legewie and Di Prete (2012), using data from Germany, argue that boys are more sensitive than girls to school resources that create a learning-oriented environment. Schools with higher shares of LE students are likely to require teachers to devote at least some attention away from male native students and therefore a reduction in the school resource of teacher time devoted to them.

Next, we separated the sample of non-LE students by race and tested for Limited English student peer effects. The results suggested on average no effects on Whites and negative effects on Blacks in math and reading. This finding is also consistent with previous research on school resources where Black students are more sensitive to beneficial resources such as smaller class sizes. Finally, to test for possible interactions of race and gender, we divide the native sample into 4 distinct groups (Black females, Black males, White females and White males) and test for LE peer effects separately for each group. Our estimated effects are summarized in Figure 1.

\section{Figure 1 - Effect of 1 percent increase on number of Limited English Students on native student Achievement by Race and Gender}

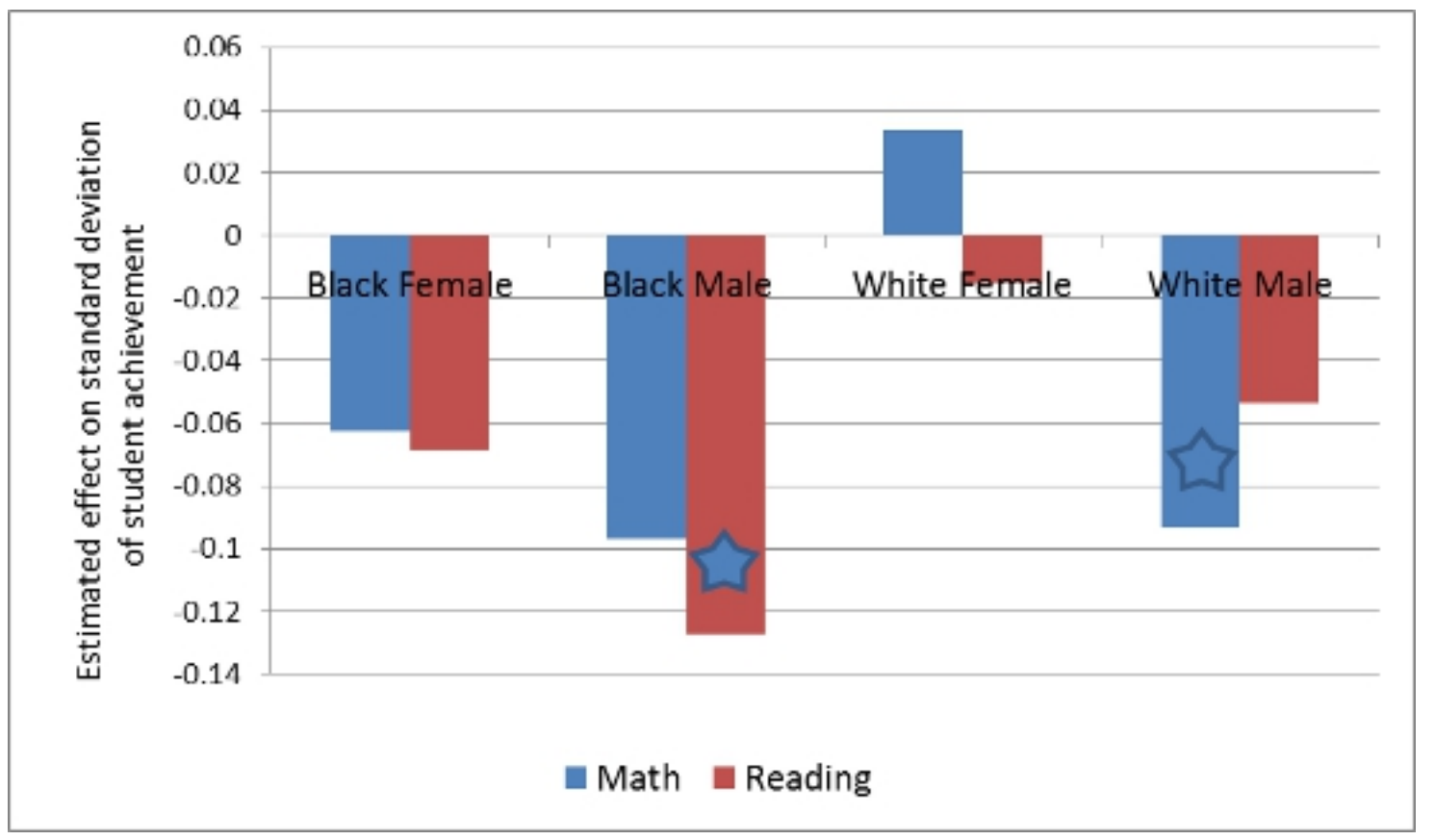

\section{Note: Starred graphs highlight estimated effects that are statistically significant}

We find that although on average Black natives experience negative LE student peer effects, the effects are only statistically significant for Black males. Our results also suggest no significant effect on White females, which is consistent with our earlier findings. However for White males we find negative LE student peer effects in math (0.09 of the standard deviation) and no significant effects in reading.

How large are these negative effects? We can put the size of the effect in context by comparing it to the estimatec effect of improving teacher quality. The largest negative effect in our results is -0.13 , the effect on Black males in reading. The mean share of Limited English students in a grade in our sample is less than 4 percent. Our estimates suggest that a 10 percentage point increase in LE students in a grade would lead to a fall of 0.013 of a standard deviation in Black males scores in reading. Research on teacher quality suggests that moving from an average teacher to one at the $84^{\text {th }}$ percentile would raise student achievement by 0.2 to 0.3 of a standard 
deviation. So if we compare the 0.01 for a large increase in LE students to 0.2 for an improvement in teacher quality, we can see that these negative effects of LE students are not large enough to justify significant policy concerns.

Why are these results important? First, they provide some evidence that increased exposure to Limited English students creates some negative peer effects and that these effects are not homogenous within the population. Finding minimal effects solely on boys suggest that fears of large negative effects of immigrant populations in schools may be unfounded. There is either a minimal impact or schools are successfully employing strategies to prevent any large effects on native students. Our findings are in contrast to Angrist and Lang (2004) who find negative peer effects on girls but not boys from the METCO program in Massachusetts. These differences in the impact of disadvantaged peers on other students suggest that our finding for North Carolina may not be generalizable across states or context. The presence of heterogeneous peer effects highlights the need for further research that examines these differences. Moreover there is need for policymakers to be mindful of these potential effects in the design and study of public policy.

This article is based on the paper "Gender and Race Heterogeneity: The Impact of Students with Limited English on Native Students' Performance" in the American Economic Review.

Featured image credit: Ben W (CC-BY-NC-2.0)

Please read our comments policy before commenting.

Note: This article gives the views of the author, and not the position of USApp-American Politics and Policy, nor of the London School of Economics.

Shortened URL for this post: http://bit.ly/VpFYkm

\section{About the author}

\section{Timothy M. Diette - Washington and Lee University}

Timothy M. Diette Is an Associate Professor of Economics at the Williams School of Commerce, Economics, and Politics at Washington and Lee University. Professor Diette conducts research on a range of issues related to the development and maintenance of human capital. Examples of recent research includes summer learning loss, the influence of school composition on future life outcomes, the effect of immigrant students on native born students, and understanding access to rigorous courses within and across schools.

Ruth Uwaifo Oyelere - Institute for the study of Labor (IZA), Germany.

Ruth Uwaifo Oyelere is currently a visiting faculty at Emory University. She is also aResearch Fellow at the Institute for the Study of Labor (IZA) Bonn Germany. Professor Oyelere's research interests fall into four main fields: development economics, education economics, labor and demographic economics, and health economics. Examples of recent research includes the effect of low intensity conflict on education attainment, the effect of immigrant students on native born students and the role of immigrant networks on homeownership before the great recession and

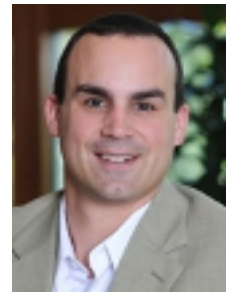
afterward. 